\title{
The Efficacy and Safety of Platelet-Rich Plasma and Adipose-Derived Stem Cells: An Update
}

\begin{abstract}
Jaehoon Choi ${ }^{*}$, Kyung Won Minn, Hak Chang Korea

During the past decade, many studies using platelet-rich plasma (PRP) or adipose-derived stem cells (ASCs) have been conducted in various medical fields, from cardiovascular research to applications for corneal diseases. Nonetheless, there are several limitations of practical applications of PRP and ASCs. Most reports of PRP are anecdotal and few include controls to determine the specific role of PRP. There is little consensus regarding PRP production and characterization. Some have reported the development of an antibody to bovine thrombin, which was the initiator of platelet activation. In the case of ASCs, good manufacturing practices are needed for the production of clinical-grade human stem cells, and in vitro expansion of ASCs requires approval of the Korea Food and Drug Administration, such that considerable expense and time are required. Additionally, some have reported that ASCs could have a potential risk of transformation to malignant cells. Therefore, the authors tried to investigate the latest research on the efficacy and safety of PRP and ASCs and report on the current state and regulation of these stem cell-based therapies.
\end{abstract}

Department of Plastic and Reconstructive Surgery, Seoul National University Hospital, Seoul National University College of Medicine, Seoul,

Keywords Mesenchymal stem cells / Platelet-rich plasma / Treatment outcome / Safety
Correspondence: Hak Chang Department of Plastic and Reconstructive Surgery, Seoul National University Hospital, Seoul National University College of Medicine, 101 Daehak-ro, Jongno-gu, Seoul 110-744, Korea

Tel: +82-2-2072-3086

Fax: +82-2-747-5130

E-mail: hchang@snu.ac.kr

*Present address: Department of Plastic and Reconstructive Surgery, Gyeongsang National University Hospital, Gyeongsang National University College of Medicine, Jinju, Korea

This article was presented at the the 69th Annual Conference of the Korean Society of Plastic and Reconstructive Surgeons on November 11-13, 2011 in Seoul, Korea.

No potential conflict of interest relevant to this article was reported.

Received: 30 Jan 2012 • Revised: 9 Feb 2012 • Accepted: 9 Feb 2012

pISSN: 2234-6163 • elSSN: 2234-6171 • http://dx.doi.org/10.5999/aps.2012.39.6.585• Arch Plast Surg 2012;39:585-592

\section{INTRODUCTION}

Generally, the use of platelet-rich plasma (PRP) or adiposederived stem cells (ASCs) in both basic research and preclinical studies is considered safer and more practical than other cellbased therapies, as they are autologous. During the past decade, many studies using PRP or ASCs have been conducted in various medical fields, from cardiovascular research to applications for corneal diseases. However, there are several limitations of practical applications of PRP and ASCs. In the case of PRP, little basic research and few preclinical studies have been conducted to assess their therapeutic potential, and although the majority of the studies that do exist have yielded excellent outcomes, most were limited case studies or series $[1,2]$. The beneficial effects of ASCs have also been proven scientifically in vitro and in vivo. However, ASCs are difficult both to handle and to make commercially from an industrial point of view. Good manufacturing practices (GMPs) are required for the production of clinicalgrade human stem cells, which involve considerable expense and time. Moreover, some have reported that ASCs could have a potential risk of transformation to malignant cells [3-9]. Therefore, we reviewed the efficacy and safety of PRP and ASCs, and then reported the current state and regulation of these stem cellbased therapies. 
Table 1 . The seven main growth factors released by platelet

Three isomers of platelet-derived growth factor (PDGF- $\alpha \alpha$, PDGF- $\alpha \beta$, and PDGF- $\beta \beta$ ) Two isomers of transforming growth factor- $\beta$ (TGF- $\beta 1$ and TGF- $\beta 2$ )

Vascular endothelial growth factor (VEGF)

Epithelial growth factor (EGF)

\section{WHAT IS PRP?}

PRP is a concentration of autologous human platelets in a small volume of plasma. PRP works via the degranulation of the $\alpha$-granules in platelets $[1,2]$. The $\alpha$-granules contain the seven main growth factors, which include three isomers of platelet-derived growth factor (PDGF- $\alpha \alpha$, PDGF- $\alpha \beta$, and PDGF- $\beta \beta$ ), two isomers of transforming growth factor- $\beta$ (TGF- $\beta 1$ and TGF- $\beta 2$ ), vascular endothelial growth factor (VEGF), and epithelial growth factor (EGF) (Table 1) [1,2]. The active secretion of these growth factors is initiated by the clotting process of blood, and begins within 10 minutes after clotting, with more than 95 percent of the presynthesized growth factors secreted within 1 hour [1]. Therefore, PRP must be developed in an anticoagulated state and be used on the application site within 10 minutes of clot initiation. After this initial burst, the platelets synthesize and secrete additional proteins for the balance of their lives (5 to 10 days) [1].

\section{EFFICACY OF PRP}

The positive effects of PRP in favoring angiogenesis processes and proliferation of undifferentiated stem cells have been demonstrated experimentally. In relation to angiogenesis, Eppley et al. [2] reported that PRP stimulated endothelial cells near their application site, favoring proliferation and formation of new capillaries. Moreover, in an in vitro study, $\mathrm{Hu}$ et al. [10] concluded that PRP is a potential contributor in possibly starting the process of angiogenesis, recruiting the endothelial cells that line blood vessels, and beginning the initiation of bone regeneration. This is because they observed mRNA expression of VEGF and PDGF in rat bone marrow stromal cell differentiation inducted by using PRP. PRP is able to stimulate undifferentiated stem cell proliferation and cell differentiation for tissue regeneration $[11,12]$. Undifferentiated stem cells migrate to the concentration of PRP growth factor, and the growth factors trigger proliferation of these cells once they are at the site [13]. Some have also implied that the value of PRP is mostly related to soft tissue healing enhancement because platelets do not contain bone morphogenic protein (BMP). Indeed, PRP does not contain any BMP and is not osteoinductive. However, all bone graft healing and osteoconduction into bony defects and around the numerous bone substitutes used today arise from adult mesenchymal stem cells and their lineage, leading to osteoblasts, all of which have already been proven to respond to PRP with accelerated bone formation $[14,15]$. In fact, the first randomized trial of PRP versus non-PRP grafts focused specifically on and documented PRP's enhancement of bone formation [14].

Successful clinical applications have been reported using PRP, such as in difficult wounds, maxillofacial bone defects, and cosmetic surgery. Although these applications have reported significant effects, the majority of the reports are anecdotal and few include controls to definitively determine the role of PRP $[1,2]$. Most are only limited case studies or series. There also have been publications that concluded that there was little or no benefit from PRP. These studies can often be traced to poor-quality PRP produced by inadequate devices $[1,2]$ because not all currently marketed PRP devices are equal, and there is little consensus regarding PRP production and characterization, which can impede the establishment of standards that are necessary to integrate the vast literature in basic and clinical science $[1,16]$. First, there is no single recommendation for the degree of increase of platelets in PRP over baseline. Some investigators have suggested that PRP should achieve a 3- to 8-fold increase in platelet concentration over baseline $[17,18]$. Since most individuals have a platelet count near the range of 250,000 per cubic milliliter, a PRP platelet count of about $1,000,000$ per cubic milliliter may be the therapeutic level. Second, the centrifugation process must be sterile and precisely suited to platelet separation from red blood cells and their sequestration in high concentrations without lysing the platelets or damaging them so that they no longer can actively secrete their growth factors.

The tests for measuring platelet viability include $\mathrm{pH}$, hypotonic stress, P-selectin, and platelet aggregation levels [19]. P-selectin is a protein contained in the inner face of the $\alpha$-granule membrane. On platelet activation, the $\alpha$-granule membrane fuses with the platelet membrane and P-selectin becomes expressed on the platelet surface, where it can be measured and the amount of platelet activation determined [20]. Better platelet quality is reflected by a lower P-selectin level. Thus, measurement of P-selectin provides valuable information regarding $\mathrm{PRP}$ preparation $[17,21]$.

The best way is to review the level of science each publication represents, assessing the quality of PRP used in each study and the controls used. Clinicians must read the literature and assess the results of studies relating to PRP as to whether devices cleared by the government are used for PRP processing, or whether platelet concentrations and growth factors are documented. 


\section{SAFETY OF PRP}

Because it is an autologous preparation, PRP is inherently safe and therefore free from concerns over transmittable diseases such as HIV, hepatitis, West Nile fever, and Cruetzfeldt-Jacob disease (CJD). In spite of this, the safety of PRP has been questioned recently. First, some have suggested based on empirical evidence that PRP may promote infections because blood agar is used in microbiology laboratories to culture bacteria [1]. However, PRP is no different in substrate than the blood clot that is formed in every wound, and therefore could not support bacterial growth any more than any other blood clot. In fact, PRP has a $\mathrm{pH}$ of 6.5 to 6.7 compared with a mature blood clot of 7.0 to 7.2. It has thus been counter-suggested that PRP actually inhibits bacterial growth [1]. Second, the most common method of platelet activation is to add calcium chloride and thrombin to the PRP $[18,21]$. In the early to mid 1990s, there were a few reports of the development of antibovine antibodies (antibovine factor V) that cross-reacted with human clotting factors in response to the use of the bovine product to provide hemostasis [22-24]. However, there is little evidence that such cross-reaction occurs for this application. This may be because current processing methods remove much more bovine factor $\mathrm{V}$ contamination, the use of bovine thrombin in PRP is low dose (200 units), most of their applications are topical with no entry into systemic circulation, and it is already clotted when it comes into contact with human tissues [2]. Related to the issue of CJD, concerns have been advanced about the use of bovine thrombin. However, bovine thrombin has a completely negative history of CJD in more than 10 million uses in a wide variety of surgeries worldwide [1]. Because the transmission vector of CJD is a prion that to date has been found only in neural tissues of the central nervous system in cattle, sheep, cats, humans, etc. and because bovine thrombin is derived solely from blood and is also heat processed for purification, it remains in standard use today in many surgeries and is the safe initiator of clotting related to PRP. Finally, sterility may be difficult to maintain during processing $[1,18]$. However, various companies are now marketing clinical autologous platelet concentrate machines that are compact table top centrifuges used at the point-of-care.

\section{WHAT ARE ASCS?}

ASCs can be derived from human adipose tissue, which can be harvested by direct excision or more commonly from lipoaspirate. Adipose tissue is a more accessible, abundant, and reliable site for the isolation of adult stem cells than bone marrow. Adipose tissues contain 100,000 MSCs in each gram of fat [25].
After collagenase digestion and subsequent centrifugation of the harvested tissue, the cell pellet, known as the stromal vascular fraction (SVF) is obtained. According to the International Society for Cellular Therapy, SVF can be considered adipose-derived stromal cells, which are cells that do not meet the requirements for 'stermness': long-term self-renewing cells that are capable of differentiation into specific, multiple cell types in vivo [11]. SVF contains a mixture of cells, which not only includes ASCs but also contains endothelial cells, smooth muscle cells, pericytes, fibroblasts, and circulating cell types such as leukocytes, hematopoietic stem cells, or endothelial progenitor cells. Due to the fact that SVF is a heterogeneous cell population, purification and subsequent expansion of ASCs from the SVF selects for a relatively homogeneous cell population, enriching for cells expressing a stromal immunophenotype, compared with the heterogeneity of unprocessed SVF.

\section{EFFICACY OF ASCS}

GMPs are needed for ASC processing because in vitro expansion is needed to obtain a large enough number of cells, and to maintain phenotypic and genotypic stability of MSCs during multiple passages. However, considerable expense and time is required, and in vitro expansion of ASCs requires approval of the Korea Food and Drug Administration (KFDA), a complicated and lengthy process. The cell-based therapy can be easily applicable to cosmetic surgery, which may have a low risk of systemic effects. Nonetheless, speed of preparation is of the essence for optimal surgical practice, especially cosmetic surgery, and thus it is a great weakness that table-top processing of cells in the operating room and reinjection is impossible.

SVF is acceptable as a coarse preparation because it is relatively quick to prepare and can provide ASCs for application sites, even though it is also likely to contain other cells. Hence, for some surgical applications, purity of ASCs may be sacrificed in favor of surgical convenience. However, most in vitro and in vivo studies draw results not from SVF, but culture-expanded ASCs, and thus the beneficial effect of SVF has not yet been proven scientifically.

SVF has been mainly used in plastic and reconstructive surgery, where it has most often been used to improve the results of fat grafting. Yoshimura's $[26,27]$ research was focused on a strategy known as cell-assisted lipotransfer, in which the SVF was isolated from half of the aspirated fat and recombined with the other half prior to reinjection. This was said to improve fat graft survival for breast augmentation or treatment of contour deformities. Other clinical trials of SVF in fat grafts included their use in the treatment of chest wall radiation necrosis [28]. Excellent 
clinical outcomes with injection of fat grafts into the chest wall have been mediated by SVF. However, the studies lacked any controls.

\section{SAFETY OF ASCS}

To apply ASCs to stem cell therapy in the human clinic, we must determine the characteristics, stability, toxicity, and tumorigenicity of ASCs in animals and then transplant them to patients.

Long-term culture can alter the quality of ASCs, including their proliferative capacity, differentiation potential, and trophic activity [29-31]. In the study of Rubio et al. [32,33], spontaneous transformation of ASCs was found to occur with prolonged culture and seemed to involve a mesenchymal-epithelial transition. However, all the data concerning the transformation were later found to be related to contamination by an epithelial cancer cell line during the experimental procedures [34,35]. Therefore, researchers must verify that the passaged ASCs are genetically stable, and must also obtain consistent data on the morphological, immunophenotypic, and differentiation characteristics.

Culture medium is commonly supplemented with serum. Serum supplementation is practical because it provides the cells with vital nutrients, attachment factors, and growth factors [36]. Fetal bovine serum (FBS), for instance, is known to be rich in growth factors and stimulates protein accretion in cell cultures [36]. It is widely known that $10 \%$ FBS supplies an ideal environment for culture and differentiation of stem cells. There are a number of clinical trials exploring the use of mesenchymal stem cells for treatment of various diseases, most of which use FBS as the culture medium $[37,38]$. However, use of xenogeneic serum can cause several problems. Viral or bacterial infections and prion transmission can arise [39]. Other possible problems are immunologic reactions. Kievits et al. [40] noted that rodents had strongly immunogenic reactions by $\beta 2$-microglobulin from bovine culture medium. Several cases in clinical trials have been also reported. After inoculating malignant melanoma patients with human peptide-pulsed dendritic cells cultured in medium supplemented with $10 \%$ fetal calf serum (FCS), the presence of IgG and IgM antibodies to $10 \%$ FCS and bovine serum albumin was observed, and an IgE autoantibody against bovine serum albumin was found from the patients with anaphylactic reactions [41]. Selvaggi et al. [42] reported that lymphocytes from HIV-1-uninfected identical twin siblings cultured in medium supplemented with 5\% FCS, anti-CD3 antibody, and interleukin-2 (100 IU/mL) for 10 days were infused into patients, and one-half of the patients developed arthus-like reactions, and antibodies to a single component of FCS were detected by double immunodiffusion [42]. These observations suggested that the therapeutic use of human lymphocytes cultured in FCS might expose the recipient to immunogenic substances with possible clinical sequelae. Third, the use of xenogeneic material in the manufacturing of human medical products can cause ethical concerns. Autologous serum (AS) is perhaps the obvious option for clinical applications, since it eliminates the problem of introducing xenogeneic or allogeneic antibodies into the patient. However, conflicting results have been reported on the superiority of AS compared to FBS in terms of proliferation rate and differentiation potential. Utilizing bone marrow-derived mesenchymal stem cells (BM-MSCs), some authors had reported higher proliferation rates using AS $[43,44]$, while others showed that AS yields similar results to FBS [45]. Additionally, so far, no reports to quantitatively verify the effect of AS on cell proliferation and differentiation of ASCs have been published. An unpublished study compared the effects of four different concentrations of AS (1\%, $2 \%, 5 \%$, and $10 \%)$ on expansion and adipogenic differentiation of ASCs using 10\% FBS as a control. Ten percent AS was at least as effective as $10 \%$ FBS with respect to the number of ASCs at the end of both isolation and expansion, whereas $1 \%$ and $2 \%$ AS were inferior (Figs. 1, 2). Nonetheless, utilizing AS for largescale stem cell production for clinical applications is impeded due to the limited quantity of AS available.

Collagenase, dispase, and hyaluronidase are some of the enzymes used to disrupt harvested adipose tissue. In their crude form, these reagents often contain contaminating amounts of endotoxin, other peptidases, and xenoproteins [46]. The most

Fig. 1. ASCs expansion using different culture medium

Expansion potential of adipose-derived stem cells (ASCs) cultured in 1\%, 2\%, 5\%, and 10\% autologous serum and 10\% fetal bovine serum at passage 2 . There were significant differences among groups by Kruskal-Wallis test $(P<0.001)$. There was also a significant difference between each of the 2 groups $\left({ }^{a} P<0.05\right)$. No significant differences were observed between 1\% autologous serum and $2 \%$ autologous serum, and 5\% autologous serum and 10\% fetal bovine serum. 10\% autologous serum showed the most prominent expansion characteristics. T-bars represent standard deviation from the mean. AS, autologous serum; FBS, fetal bovine serum.

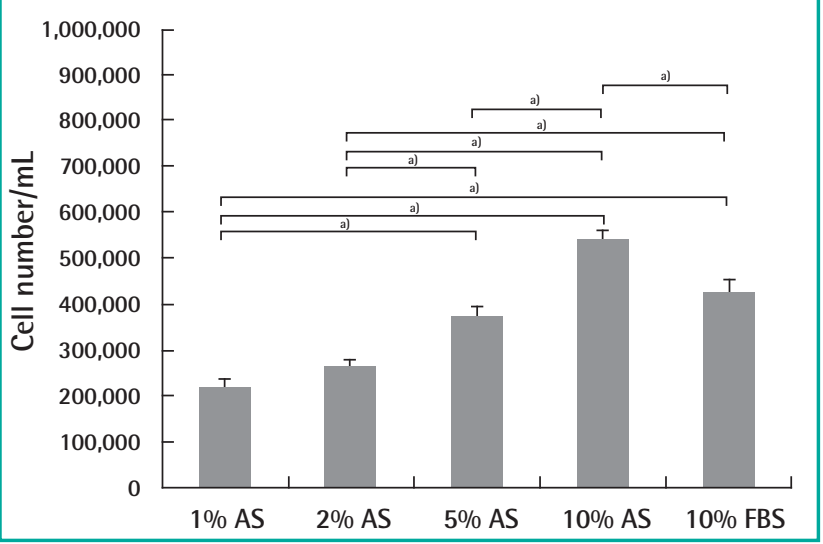


commonly used enzyme among these is collagenase, which was obtained from Clostridium histiolyticum. It is marked 'for research use only', or 'for R\&D use only', and is not licensed as a medicine. In the process of cell isolation, several washes are performed to eliminate collagenase, but there still remains a possibility that there is a remnant of collagenase. A maximum allowable concentration of collagenase in the human body has not been established. Although this research has not yet been published, the authors verified the safety of the ASC preparation. The residual volume of collagenase was investigated according to the frequency of washing following digestion of adipose tissue with $0.1 \%$ type IA collagenase (Sigma-Aldrich, St. Louis, MO, USA) for 30 minutes. The collagenase activity was observed with N-(3-[2-Furyl]acryloyl)-Leu-Gly-Pro-Ala (FALGPA)

Fig. 2. ASCs differentiation using different culture medium

Adipogenic differentiation of adipose-derived stem cells (ASCs) cultured in 1\%,2\%,5\%, and 10\% autologous serum and 10\% fetal bovine serum at passage 4 . There were significant differences among groups by Kruskal-Wallis test $(P<0.001)$. There was a significant difference between each of the 2 groups $\left({ }^{\text {al }} P<0.05\right)$. No significant differences were observed between 1\% autologous serum and 2\% autologous serum, and 2\% autologous serum and 5\% autologous serum. The differentiation capacity depended on the serum concentration between autologous serum groups. Ten percent fetal bovine serum had a significantly higher differentiation capacity than 10\% autologous serum when compared with 10\% fetal bovine serum with $10 \%$ autologous serum $(P=0.0004)$. $A S$, autologous serum; $F B S$, fetal bovine serum.

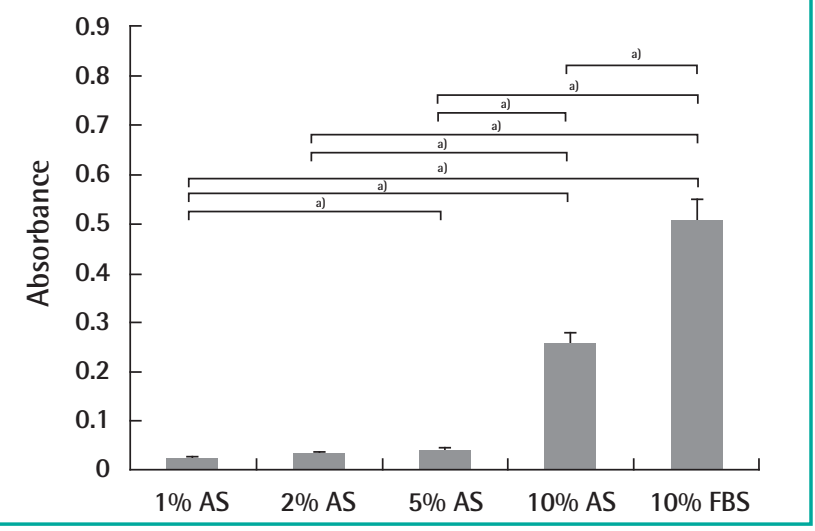

assay and Ninhydrin assay. In all measured results, no residual enzyme activity was observed after 2 washes (Tables 2, 3). In vivo toxicity caused by residual collagenase after washing was investigated. BALB/c nude mice were subcutaneously injected with ASCs, which were cultured from adipose tissues, and were washed one and three times after collagenase treatment. No toxicological effect on the liver or heart was observed after 4 weeks (Table 4). Furthermore, the BALB/c nude mice were subcutaneously injected with $2 \times 10^{6}$ cultured ASCs, and no tumors was detected for 4 months regardless of the frequency of washing.

Reports have shown that the immunosuppressive capacity of ASCs may in some cases favor the growth of tumor cells but contradictory results exist. Muehlberg et al. [3] reported that

Table 2. FALGPA assay for collagenase activities at different number of washing or different inhibitors

\begin{tabular}{|c|c|c|c|}
\hline \multirow{2}{*}{$\begin{array}{l}\text { No. of } \\
\text { washing }\end{array}$} & \multicolumn{3}{|c|}{ Inhibitors $\left(\mathrm{mL}^{-1}\right)$} \\
\hline & Saline & FBS & AS \\
\hline No & 0.463 & 0.400 & 0.451 \\
\hline One time & 0.111 & 0.110 & 0.107 \\
\hline Two times & 0.117 & 0.106 & 0.105 \\
\hline Three times & 0.105 & 0.106 & 0.106 \\
\hline Four times & 0.106 & 0.105 & 0.106 \\
\hline Five times & 0.105 & 0.106 & 0.105 \\
\hline
\end{tabular}

Table 3. Ninhydrin assay for collagenase activities at different number of washing or different inhibitors

\begin{tabular}{|lccc|}
\hline \multirow{2}{*}{$\begin{array}{l}\text { No. of } \\
\text { washing }\end{array}$} & \multicolumn{3}{c|}{ Inhibitors $\left(\mathrm{mL}^{-1}\right)$} \\
\cline { 2 - 4 } & Saline & FBS & AS \\
\hline No & 353 & 370 & 356 \\
One time & 51 & 51 & 55 \\
Two times & 40 & 37 & 40 \\
Three times & 38 & 36 & 37 \\
Four times & 34 & 38 & 40 \\
Five times & 39 & 41 & 43 \\
\hline $\begin{array}{l}\text { Values are presented as means. } \\
\text { FBS, fetal bovine serum; AS, autologous serum. }\end{array}$ \\
\hline
\end{tabular}

Table 4. Microscopic observations of NOD/SCID mice subcutaneously treated with hASCs in 4-week toxicity study

\begin{tabular}{|c|c|c|c|c|c|c|}
\hline \multirow{2}{*}{$\frac{\text { Sex of animal }}{\text { Group ( } n=10 \text { per group) }}$} & \multicolumn{3}{|c|}{ Male } & \multicolumn{3}{|c|}{ Female } \\
\hline & Control (saline) & 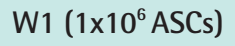 & W3 (1x10 & Control (saline) & W1 (1x10 ${ }^{6}$ ASCs) & W3 $\left(1 \times 10^{6}\right.$ ASCs $)$ \\
\hline \multicolumn{7}{|l|}{ Liver } \\
\hline Focal inflammation & 1 & 0 & 2 & 0 & 0 & 1 \\
\hline Focal granuloma & 0 & 1 & 0 & 0 & 0 & 0 \\
\hline \multicolumn{7}{|l|}{ Heart } \\
\hline Focal calcification & 0 & 1 & 1 & 2 & 1 & 1 \\
\hline
\end{tabular}


mouse ASCs in a murine model home to the tumor site and promote tumor growth in vivo, not only when co-injected locally, but also when injected intravenously. Yu et al. [4] showed that human ASCs together with tumor cells transplanted subcutaneously or intracranially into BALB/c nude mice promoted tumor growth. Recent reports have documented the ability of ASCs to promote the proliferation of active breast cancer cells in vitro and in vivo via paracrine mechanisms [5-8]. A comparable study has indicated that ASCs promote the growth of prostate cancer cell lines transplanted into immunodeficient mice [9]. Conversely, Kucerova et al. [47] showed that cytosine deaminase-expressing ASCs deliver the cytosine deaminase transgene to the site of tumor formation and mediate a strong antitumor effect in vivo. Cousin et al. [48] reported that ASCs strongly inhibit proliferation of pancreatic ductal adenocarcinoma cells, both in vitro and in vivo by interfering with the proliferation of tumor cells by altering cell cycle progression. These divergent reports may in part be explained by variations in the protocols used in vivo and in vitro. However, although an experimental model is never completely consistent with the complex mechanisms in nature, these contradictory results indicate that the work is far from done, and further studies and consensual protocols are necessary to fully elucidate the true effect of ASCs on tumor formation.

\section{REGULATIONS}

New regulations by the Food and Drug Administration (FDA) and EU classify procedures according to the degree of manipulation involved and the risk of adverse processing-related events [49-53]. Minimal manipulation, such as cryopreservation of autologous peripheral blood progenitor cells (PBPC), may be performed using good tissue practices (GTPs), a level of control similar to that already practiced by most clinical laboratories. With regards to more-than-minimal manipulation, an elevated degree of process control and laboratory complexity is required, which is known as good manufacturing processes. More-thanminimal manipulation includes transduction, ex vivo expansion, activation, combination with non-tissue components, use for other than the tissue's normal function, and transplantation of unrelated allogeneic cells and tissues [49]. In the United States all ASC isolation and subsequent biological activity and the related devices and laboratories that engage in proliferating or differentiating ASCs before introduction into the subject for a specific medical condition require oversight and FDA validation and premarket approval because of possible safety concerns. Currently, there are no FDA approved ASC isolation devices, ASC procedures for use in medical conditions, or ASC clinics in the United States.
In Korea, whether or not culture and proliferation are included in the process is important. According to KFDA officials, when culture and proliferation are undertaken, there is a possibility of modification of the nature of the stem cell line. If cultureexpanded stem cells are used, approval of the KFDA is needed. However, in a clinical procedure with PRP or SVF, if no fees are charged, with the consent of the patient, it is possible to use these therapies without approval of the KFDA. Moreover, for cosmetic purposes the procedure can be performed without limitation under the responsibility of the hospital and the prices can be negotiated. Nevertheless, instruments used for PRP or SVF processing need approval of the KFDA. The world's first stem cell therapy is in Korea, known as Hearticellgram-AMI, consisting of an injection of somatic stem cells cultured from the bone marrow into the coronary arteries of patients who have suffered from acute myocardial infarction. In the fields of plastic surgery, the clinical procedure with adipocytes differentiated from ASCs for the treatment of depressed scars was approved by the KFDA [54].

\section{CONCLUSIONS}

To date, the reports about PRP are anecdotal and few include controls to determine the specific role of PRP. Most are only limited case studies or series. The majority of peer-reviewed publications on human trials using ASCs are phase I safety trials and case reports. The beginning of the scientific study about PRP and ASCs in plastic surgery has come late, but there are many opportunities for moving forward because we can easily obtain adipose tissue and apply these therapies to clinically lowrisk cases such as cosmetic surgery and reconstruction of tissue. Therefore, we can overcome this obstacle.

\section{REFERENCES}

1. Marx RE. Platelet-rich plasma: evidence to support its use. J Oral Maxillofac Surg 2004;62:489-96.

2. Eppley BL, Pietrzak WS, Blanton M. Platelet-rich plasma: a review of biology and applications in plastic surgery. Plast Reconstr Surg 2006;118:147e-159e.

3. Muehlberg FL, Song YH, Krohn A, et al. Tissue-resident stem cells promote breast cancer growth and metastasis. Carcinogenesis 2009;30:589-97.

4. Yu JM, Jun ES, Bae YC, et al. Mesenchymal stem cells derived from human adipose tissues favor tumor cell growth in vivo. Stem Cells Dev 2008;17:463-73.

5. Donnenberg VS, Zimmerlin L, Rubin JP, et al. Regenerative therapy after cancer: what are the risks? Tissue Eng Part B 
Rev 2010;16:567-75.

6. Zimmerlin L, Donnenberg AD, Rubin JP, et al. Regenerative therapy and cancer: in vitro and in vivo studies of the interaction between adipose-derived stem cells and breast cancer cells from clinical isolates. Tissue Eng Part A 2011;17:93106.

7. Jotzu C, Alt E, Welte G, et al. Adipose tissue-derived stem cells differentiate into carcinoma-associated fibroblast-like cells under the influence of tumor-derived factors. Anal Cell Pathol (Amst) 2010;33:61-79.

8. Zhao M, Dumur CI, Holt SE, et al. Multipotent adipose stromal cells and breast cancer development: Think globally, act locally. Mol Carcinog 2010;49:923-7.

9. Prantl L, Muehlberg F, Navone NM, et al. Adipose tissuederived stem cells promote prostate tumor growth. Prostate 2010;70:1709-15.

10. $\mathrm{Hu} \mathrm{Z}$, Peel SA, Ho SK, et al. Platelet-rich plasma induces mRNA expression of VEGF and PDGF in rat bone marrow stromal cell differentiation. Oral Surg Oral Med Oral Pathol Oral Radiol Endod 2009; 107:43-8.

11. Horwitz EM, Le Blanc K, Dominici M, et al. Clarification of the nomenclature for MSC: The International Society for Cellular Therapy position statement. Cytotherapy 2005; 7:393-5.

12. Hausman GJ, Richardson RL. Adipose tissue angiogenesis. J Anim Sci 2004;82:925-34.

13. Kevy S, Jacobson M, Benoit P. The biology of platelet concentrate as prepared by the Harvest Technologies SmartPReP System. Proceedings of the 3rd Annual Meeting of Techvest Conference on Tissue Repair, Replacement, and Regeneration; 2001 Oct 23; New York, USA.

14. Marx RE, Carlson ER, Eichstaedt RM, et al. Platelet-rich plasma: Growth factor enhancement for bone grafts. Oral Surg Oral Med Oral Pathol Oral Radiol Endod 1998;85: 638-46.

15. Slater M, Patava J, Kingham K, et al. Involvement of platelets in stimulating osteogenic activity. J Orthop Res 1995;13: 655-63.

16. Zimmermann R, Arnold D, Strasser E, et al. Sample preparation technique and white cell content influence the detectable levels of growth factors in platelet concentrates. Vox Sang 2003;85:283-9.

17. Kevy SV, Jacobson MS. Comparison of methods for point of care preparation of autologous platelet gel. J Extra Corpor Technol 2004;36:28-35.

18. Gonshor A. Technique for producing platelet-rich plasma and platelet concentrate: background and process. Int J Periodontics Restorative Dent 2002;22:547-57.
19. Jameson CA. Autologous platelet concentrate for the production of platelet gel. Lab Med 2007;38:39-42.

20. Harrison P, Cramer EM. Platelet alpha-granules. Blood Rev 1993;7:52-62.

21. Eppley BL, Woodell JE, Higgins J. Platelet quantification and growth factor analysis from platelet-rich plasma: implications for wound healing. Plast Reconstr Surg 2004;114: 1502-8.

22. Christie RJ, Carrington L, Alving B. Postoperative bleeding induced by topical bovine thrombin: report of two cases. Surgery 1997; 121:708-10.

23. Rapaport SI, Zivelin A, Minow RA, et al. Clinical significance of antibodies to bovine and human thrombin and factor V after surgical use of bovine thrombin. Am J Clin Pathol 1992;97:84-91.

24. Zehnder JL, Leung LL. Development of antibodies to thrombin and factor $V$ with recurrent bleeding in a patient exposed to topical bovine thrombin. Blood 1990;76:2011-6.

25. Sen A, Lea-Currie YR, Sujkowska D, et al. Adipogenic potential of human adipose derived stromal cells from multiple donors is heterogeneous. J Cell Biochem 2001;81:312-9.

26. Yoshimura K, Sato K, Aoi N, et al. Cell-assisted lipotransfer for cosmetic breast augmentation: supportive use of adipose-derived stem/stromal cells. Aesthetic Plast Surg 2008;32:48-55.

27. Yoshimura K, Sato K, Aoi N, et al. Cell-assisted lipotransfer for facial lipoatrophy: efficacy of clinical use of adiposederived stem cells. Dermatol Surg 2008;34:1178-85.

28. Rigotti G, Marchi A, Galie M, et al. Clinical treatment of radiotherapy tissue damage by lipoaspirate transplant: a healing process mediated by adipose-derived adult stem cells. Plast Reconstr Surg 2007;119:1409-22.

29. Wislet-Gendebien S, Leprince P, Moonen G, et al. Regulation of neural markers nestin and GFAP expression by cultivated bone marrow stromal cells. J Cell Sci 2003;116:3295302.

30. Bonab MM, Alimoghaddam K, Talebian F, et al. Aging of mesenchymal stem cell in vitro. BMC Cell Biol 2006;7:14.

31. Briquet A, Dubois S, Bekaert S, et al. Prolonged ex vivo culture of human bone marrow mesenchymal stem cells influences their supportive activity toward NOD/SCIDrepopulating cells and committed progenitor cells of B lymphoid and myeloid lineages. Haematologica 2010;95:47-56.

32. Rubio D, Garcia-Castro J, Martin MC, et al. Spontaneous human adult stem cell transformation. Cancer Res 2005;65: 3035-9.

33. Rubio D, Garcia S, De la Cueva T, et al. Human mesenchymal stem cell transformation is associated with a mesenchy- 
mal-epithelial transition. Exp Cell Res 2008;314:691-8.

34. de la Fuente R, Bernad A, Garcia-Castro J, et al. Retraction: Spontaneous human adult stem cell transformation. Cancer Res 2010;70:6682.

35. Garcia S, Bernad A, Martin MC, et al. Pitfalls in spontaneous in vitro transformation of human mesenchymal stem cells. Exp Cell Res 2010;316:1648-50.

36. Herrera B, Inman GJ. A rapid and sensitive bioassay for the simultaneous measurement of multiple bone morphogenetic proteins. Identification and quantification of BMP4, BMP6 and BMP9 in bovine and human serum. BMC Cell Biol 2009; 10:20.

37. Le Blanc K, Rasmusson I, Sundberg B, et al. Treatment of severe acute graft-versus-host disease with third party haploidentical mesenchymal stem cells. Lancet 2004;363:143941.

38. Bang OY, Lee JS, Lee PH, et al. Autologous mesenchymal stem cell transplantation in stroke patients. Ann Neurol 2005; 57:874-82.

39. Klein R, Dumble LJ. Transmission of Creutzfeldt-Jakob disease by blood transfusion. Lancet 1993;341:768.

40. Kievits F, Boerenkamp WJ, Ivanyi P. H-2-dependent binding of xenogeneic beta 2-microglobulin from culture media. J Immunol 1988;140:4253-5.

41. Mackensen A, Drager R, Schlesier M, et al. Presence of IgE antibodies to bovine serum albumin in a patient developing anaphylaxis after vaccination with human peptide-pulsed dendritic cells. Cancer Immunol Immunother 2000;49:152-6.

42. Selvaggi TA, Walker RE, Fleisher TA. Development of antibodies to fetal calf serum with arthus-like reactions in human immunodeficiency virus-infected patients given syngeneic lymphocyte infusions. Blood 1997;89:776-9.

43. Shahdadfar A, Fronsdal K, Haug T, et al. In vitro expansion of human mesenchymal stem cells: choice of serum is a determinant of cell proliferation, differentiation, gene expression, and transcriptome stability. Stem Cells 2005;23:1357-66.

44. Shigeno Y, Ashton BA. Human bone-cell proliferation in vitro decreases with human donor age. J Bone Joint Surg $\mathrm{Br}$ 1995;77:139-42.
45. Yamamoto N, Isobe M, Negishi A, et al. Effects of autologous serum on osteoblastic differentiation in human bone marrow cells. J Med Dent Sci 2003;50:63-9.

46. Williams SK, McKenney S, Jarrell BE. Collagenase lot selection and purification for adipose tissue digestion. Cell Transplant 1995;4:281-9.

47. Kucerova L, Altanerova V, Matuskova M, et al. Adipose tissuederived human mesenchymal stem cells mediated prodrug cancer gene therapy. Cancer Res 2007;67:6304-13.

48. Cousin B, Ravet E, Poglio S, et al. Adult stromal cells derived from human adipose tissue provoke pancreatic cancer cell death both in vitro and in vivo. PLoS One 2009;4:e6278.

49. Harvath L. Food and Drug Administration's proposed approach to regulation of hematopoietic stem/progenitor cell products for therapeutic use. Transfus Med Rev 2000; 14:104-11.

50. European Medicines Agency. DIRECTIVE 2001/83/EC of the European Parliament and of the Council on the Community code relating to medicinal products for human use [Internet]. Lodon: The European Parliament and of the Council of the Community; c2012 [cited 2012 Jan 30]. Available from: http://www.emea.europa.eu/pdfs/human/pmf/2001-83EC.pdf.

51. European Medicines Agency. Guideline on human cell-based medicinal products [Internet]. Lodon: The European Parliament and of the Council of the Community; c2012 [cited 2012 Jan 30]. Available from: http:// www.emea.europa. eu/pdfs/human/cpwp/41086906enfin.pdf.

52. Rehmann W, Morgan G. The regulation of advanced therapies: perspectives from the EU [Internet]. Lodon: Taylor Wessing; c2012 [cited 2012 Jan 30]. Available from: http:// www.taylorwessing.com/uploads/tx_siruplawyermanagement/The_Regulation_of_Advanced_Therapies.pdf.

53. Halme DG, Kessler DA. FDA regulation of stem-cell-based therapies. N Engl J Med 2006;355:1730-5.

54. Kim M, Kim I, Lee SK, et al. Clinical trial of autologous differentiated adipocytes from stem cells derived from human adipose tissue. Dermatol Surg 2011;37:750-9. 